This is an electronic reprint of the original article. This reprint may differ from the original in pagination and typographic detail.

Author(s): Ylönen, Hannu; Kasi, Marjo; Opperbeck, Annika; Haapakoski, Marko; Sundell, Janne

Title: $\quad$ How Do Infanticidal Male Bank Voles (Myodes glareolus) Find the Nest with Pups?

Year: $\quad 2017$

Version:

Please cite the original version:

Ylönen, H., Kasi, M., Opperbeck, A., Haapakoski, M., \& Sundell, J. (2017). How Do Infanticidal Male Bank Voles (Myodes glareolus) Find the Nest with Pups?. Ethology, 123(2), 105-112. https://doi.org/10.1111/eth.12579

All material supplied via JYX is protected by copyright and other intellectual property rights, and duplication or sale of all or part of any of the repository collections is not permitted, except that material may be duplicated by you for your research use or educational purposes in electronic or print form. You must obtain permission for any other use. Electronic or print copies may not be offered, whether for sale or otherwise to anyone who is not an authorised user. 


\section{How do infanticidal male bank voles (Myodes glareolus) find the nest with pups?}

Hannu Ylönen ${ }^{1}$, Marjo Kasi ${ }^{2}$, Annika Opperbeck ${ }^{1}$, Marko Haapakoski ${ }^{1}$ and Janne Sundell ${ }^{3}$,

1 Konnevesi Research Station, Department of Biological and Environmental Science, P.O.Box 35, FI-40014 University of Jyväskylä, Finland,

${ }^{2}$ Department of Biosciences, P.O.Box 65, FI-00014 University of Helsinki, Finland

${ }^{3}$ Lammi Biological Station, University of Helsinki, Pääjärventie 320, 16900 Lammi, Finland

Author for correspondence: Hannu Ylönen, Konnevesi Research Station, Department of Biological and Environmental Science, P.O.Box 35, FI-40014 University of Jyväskylä, Finland, email : hannu.j.ylonen@jyu.fi 
Infanticide, the killing of conspecific young occurs in most mammal species, like in our study species, the bank vole (Myodes glareolus). Infanticide by adult males is regarded as a strong factor affecting recruitment of young into population. It is considered as an adaptive behaviour, which may increase male fitness via resource gain or an increased access to mates. When an intruder is approaching the nest, the mother should not be present, as her nest guarding is very aggressive and successful. Pups use ultrasonic vocalisation to call their mother when mother leaves nest for foraging but it is not know which cues do infanticidal males use to find the nest with vulnerable pups to commit infanticide? We studied whether the pups' sounds or the olfactory cues of the nest guide the males of known infanticidal behavioural trait towards the nest with vulnerable pups. Four nest boxes in a large indoor arena offered different nesting cues; nest odour, pup vocalization, both odour and sound or control with no cue. The result showed that infanticidal males were more active in their searching behaviour than non-infanticidal males and seemed to target the nest providing only acoustic cues. Four of the males, all infanticidal, intruded the nest box. Infanticidal males seem to actively search for nests with vulnerable pups by eavesdropping pup begging calls for absent mother. However, under natural conditions mother presence and aggressive nest protection may be an effective counter-strategy against strange male infanticide. When trapping study voles from the wild we monitored occurrence of male infanticide across the breeding season from early to late summer. Proportion of infanticidal males was between 25 $29 \%$ of all males tested along the breeding season. Our results suggest that male infanticide seems to cause a stable threat for pup mortality in increasing breeding season density.

Key words: nest mortality, eavesdropping, acoustic, olfactory, ultrasound, Myodes =

\section{Clethrionomys}




\section{Introduction}

Nest mortality is one hidden population regulation factor in vertebrates (Krebs 2003). Its impact and magnitude are very difficult to determine in the wild. This is especially true, if nests are placed cryptically to protect the vulnerable eggs, pups or nestlings, or if nests are hidden in holes and cavities or inside dense vegetation. Nest mortality can be caused by several factors like the caring or incubating parent killed by predator where the whole nest is lost, by nest-parasites, like cuckoo (Davies 2015) or the African honeyguide (Spottiswoode \& Koorevaar 2012), or like in most cases direct predation. Nest predators are often specialists, like snakes or lizards in warm or hot regions (Weatherhead \& Blouin-Demers 2004) or small mustelids (Järvinen 1985) and shrews (Liesenjohan et al. 2011) in temperate and boreal regions. Mortality impact of all these functional nest-predator groups is still unknown as the range and magnitude of nest mortality is extremely difficult to assess. The common feature of a nest predator on passerine birds and small mammals is small size enabling entering to nest holes or to live in the same micro-world like the prey with their hidden nests.

A special case of nest predation is infanticide, killing of conspecific young (Hausfater \& Hrdy 1984, 2008). Infanticide occurs in most mammal species and in many other vertebrate species, like birds (Moller 1988, Robertson \& Stutchbury 1988) as well as in many invertebrates (Ichikawa 1994, Schneider \& Lubin 1996, 1997, Hausfater \& Hrdy 2008). It is common in rodents (Wolff 1993) with vulnerable altrical pups in the nest, like in our study species, the bank vole (Myodes glareolus; Ylönen et al. 1997, Korpela et al. 2010). Infanticide is committed by both females and males. However, infanticide by adult males related to their wider movements, male-biased dispersal and male-turnover in populations is regarded as a far stronger factor affecting recruitment of young into population than infanticide committed by females (e.g. Ylönen et al. 1997, Andreassen and Gundersen 2006, 
Opperbeck et al. 2012, Lukas \& Huchard 2014). Infanticide is widely considered as an adaptive behaviour, which may increase male fitness via resource gain or an increased access to mates (Agrell et al. 1998). Adaptive gain in resources or future mating success depend on competition pressure by conspecifics with similar aims. Population density is increasing with advancing breeding season, and thus it can be predicted that per capita gain for committing infanticide would be greater in low densities of early breeding season (Opperbeck et al. 2012). However, there is an alternative view that numbers of potentially infanticidal individuals would be greater under high densities (Korpela et al. 2010, 2011), despite of intraspecific competition and social harassment, possibly affecting or hindering success of an infanticidal act. Studies monitoring proportions of infanticidal individuals along the population density gradient over breeding season are lacking.

Small mammals are considered to be profoundly olfactory communicators. Social odours signal male dominance and quality for mate selecting females (Horne \& Ylönen 1996, 1998), predators, like weasels, use small rodent sexual odours for hunting (Cushing 1985) and prey voles use weasel odour as a measure of fear, predation risk (Ylönen \& Ronkainen 1994, Ylönen et al. 2006, Ylönen \& Brown 2007). However, acoustic communication is used as well and one special case is the communication between pups in the nest and mother, if absent from nest, i.e. the pups are calling the mother back for lactation (Kober et al. 2007). Acoustic communication from pups to mother is a mixture of sound hearable by us and ultrasound vocalization (USV) (Smith 1972, Wöhr et al. 2008). If these calls are heard by the mother, they should be heard by males too, regardless if the male is a threat for infanticide or not. 
This study aimed at determining which cues, olfactory or acoustic ones lead male conspecifics to unprotected bank vole nest, how males are moving in the vicinity of nest and whether the infanticidal status of the male affects their behaviour to find the nest with pup inside. We have shown previously that bank vole males (Ylönen et al. 1997, Agrell et al. 1998, Vihervaara et al. 2010, Opperbeck et al. 2012) as other small rodent males (Blumstein 2000) are infanticidal. Further, we have shown that threat of infanticide is so strong that bank vole females leave the nest with pups only for as short time as possibly e.g. for mating (Klemme et al. 2012) and that if mother is present at the nest she viciously protects the nest (Ylönen \& Horne 2002). This study focused on how nest odour and pup vocalisation affect male searching behaviour for unprotected nests and if the searching behaviour differs between infanticidal and non-infanticidal males. Basing on our experience on the importance of olfactory communication and odour cues for rodents in general and for the bank vole, we hypothesised that males will used both odour and acoustic cues to find the unprotected nest. Further, infanticidal males should use these cues more carefully than non-infanticidal males, be more active in their nest searching behaviour and possibly, try to intrude the nest more often than the non-infanticidal males.

The males used in the experiment were trapped from the wild along the increasing population density over the breeding season and tested in the laboratory for their infanticidal status. Therefore, our material allows us to answer the question if the frequency of male infanticidal trait varies over the breeding season.

\section{Material and Methods}




\section{Study species and occurrence of infanticide}

Infanticide is occurring in the bank vole both in males and females, (Ylönen et al. 1997, Vihervaara et al. 2010). The ratio of infanticidal males in wild population is regarded to be around $30-50 \%$ and in some laboratory data sets up to $80 \%$ of tested males commit killing on a non-protected pup if they had the opportunity (Ylönen et al. 1997, Ylönen \& Horne 2002). The threat for the pups is greatest when pups are less than ten days old (Ylönen et al. 1997, Ylönen \& Horne 2002, Korpela et al. 2010). The mating system of bank voles is promiscuous and males provide no parental care. It is assumed, that in the bank vole, post-partum mating, i.e. mating shortly after delivery, is the most common mode of reproduction (Klemme et al. 2012). Mating multiply with many resident males during one oestus to confuse paternity is regarded as an effective counter-strategy against infanticide (Klemme \& Ylönen 2010), because killing own pups would decrease males fitness. Another effective female counter strategy is aggressive nest defence (Ylönen \& Horne 2002).

\section{Capture of study animals and testing for infanticidal behaviour}

The bank vole densities in forest around Konnevesi Research Station in summer of the study year 2011 resembled peak density of a multiannual vole population cycle typical for Central Finland (Rikalainen 2012). Actually, it was the second peak year after 2010 and thus the population densities in the beginning of the study trapping in May were already high, around 60 captured voles in 100 trap nights. Until August population densities doubled to ca. 120 voles/100 trap nights and during the subsequent winter the populations crashed (Rikalainen 2012, E. Koskela, pers. comm.). Thus for our infanticide study it was easy to capture voles already in spring and early summer and the trapping effort was not as intensive during July and August like in May. Sample sizes were, however, large enough to monitor the frequency of infanticidal individuals in the wild along the increasing densities with advancing breeding 
season. For this purpose we divided the animals to spring cohort captured in April and May, early summer animals captured in June and late summer animals captured in July and August (Table 1.). After capture the male voles were housed individually in standard laboratory rodent cages of the size $42 \times 26 \times 15 \mathrm{~cm}$. The cages were equipped with wood shavings, hay as bedding, rodent food pellets and fresh water ad libitum, and maintained under standard conditions (18 h light : $6 \mathrm{~h}$ dark; $20^{\circ} \mathrm{C}$ ), thus the laboratory conditions corresponded roughly the natural light-dark regime during summer.

All males selected for the study were mature or submature individuals with a minimum weight of $18 \mathrm{~g}$, as these cohorts are regarded most prone to commit infanticide (Ylönen et al. 1997, Vihervaara et al. 2010). As there is some information that mating will inhibit infanticide behavior of males (McCarthy \& vomSaal 1986, Perrigo et al. 1993, Vihervaara et al. 2010) we kept wild-caught males in the laboratory for three weeks before the first infanticide test. This time period resembles roughly the time that possible sire of the male would have reached the age of 10 days or more, after which the infanticidal tendency of the male should return (Vihervaara et al. 2010 and refs. therein). The second infanticide test was done in the fifth week after capture. If both tests revealed the same infanticidal status, the male was classified as infanticidal or non-infanticidal accordingly. If the tests gave a different result, the third test was carried out two days after the second test and the status of the male was the result of the last test (in all cases the result of the third test was the same as the second one two days before). Tests were done as described by Vihervaara et al (2010). In short, an animal was released into a rodent cage $(52 \times 31 \times 19 \mathrm{~cm})$ containing a pup of $2-5$ days old inside a small wire mesh tube $(6 \mathrm{~cm}$ length, $1.5 \mathrm{~cm}$ in diameter, mesh size $1.5 \mathrm{~mm})$. The pup originated from the laboratory colony and was unrelated to the tested male. Behaviour of the male was observed from the next room through a mirror window for 10 
minutes or until it showed clear aggressive behavior (rolling, scratching or biting the tube). If the latter happened, the individual was classified as infanticidal $(\operatorname{Infa}+)$. The pup was returned to its mother after the test and after each trial, the cage and the tube were rinsed with $70 \%$ ethanol.

Laboratory experiment : Do odour and sound cues of the nest guide the males to the nest?

The nest-search experiment was conducted in a large $7 \times 7$ meter indoor arena divided into four equal squares to monitor male movements and activity (Fig. 1.). In each corner there was a wooden nest box of $25 \times 25 \times 15 \mathrm{~cm}$ placed one meter apart from the corner walls. Each nest box had two entrance tubes directed parallel to both walls. This was due to provide nest box cues effectively to an animal possibly moving along or close to the walls. The tubes allowed easy determination if the animal was keen on the cue provided but the tube ended with a wire mesh preventing the animals to enter the nest box. The nest boxes were containing vole nest cues; acoustic, olfactory, or both cues of a nest with pups. A control nest box had a novel sound cue (see below). Between each experiment the location of nest boxes with different cues was changed one step clockwise to avoid any preference for a certain corner of the arena.

The nest box cues and their production was as follows :

1. Sound. Nest box contained a playback device Avisoft ${ }^{\circledR}$ Ultrasonic Dynamic Speaker ScanSpeak, playing the vocalization of a pup of the age under five days. Sound was recorded from nest where mother was taken out and pups were left alone. The recording was done in a sound-proof room using a Avisoft ${ }^{\circledR}$ UltraSoundGate $416 \mathrm{hb}$ recorder. The repeated sound track over 30 minutes contained both hearable pup vocalization and ultrasound vocalization (USV). This nest box did not contain any bedding. 
2. Odour. Nest box had a cup of $1.8 \mathrm{dl}$ wood shaving bedding from a nest with mother and her litter of ca. 5-days old. The bedding had not been changed a week before delivery of the mother.

3. Both sound playback and nest odour

4. Control. A nest box with playback device with a novel sound recorded like in 1 . The sound was rustle of a plastic bag, with no ultrasounds and it was play-backed with the same volume than the pup vocalization. No odour cue was present.

At first the male vole was released to acclimatize on the arena for $30 \mathrm{~min}$. During this time the nest boxes were empty. After this the male was captured to a start box in the middle of the arena and the nest boxes were filled with bedding and the playback was made ready. After 5minutes calming, the male was released from the start box and its behaviour was monitored for 30 minutes. The observed behaviours were staying still or freeze, activity and moving, crossing the line between the four subareas of the arena, approaching and inspecting the nest box and intruding the box (so that the vole was fully inside the nest hole tube). All changes in behaviour were recorded, and if the behaviour remained the same (e.g. staying still) it was recorded every minute.

We used in total 32 infanticidal and 32 non-infanticidal male voles in the experiment. Of the non-infanticidal voles 15 and of the infanticidal 7 stayed passive during the whole observation period and were excluded from the analysis. After the 30-min trial the male was returned to its cage, nest boxes and surroundings of the nest boxes were cleaned with $70 \%$ alcohol. After a round of four trials nest boxes were removed from the arena and the whole floor was washed with alcohol. 


\section{Ethical statement}

Trapping voles, animal housing and all experiments were conducted following the ethical guidelines of the Board for Animal Experimentation ELLA, the permission number ESAVI/3793/04.10.03/2011. All infanticide trials were done so that the pup was protected from any injury by a wire mesh tube.

\section{Statistical analyses}

Statistical test was conducted with R version 3.2.3 (R Core Team 2015). Season effect and vole's first choice were analyzed with general linear model with poison error structure by using glm package in R. In season analysis count number of voles in each season / infanticidal class were used as a dependent variable and infanticidal status with interaction with season as explaining variables. First choice was analyzed by using count number of voles first chosen nest box as a dependent variable and interaction of infanticidal status and the nest box manipulation as explaining variables. Voles space use was analyzed as the number of visits to the area around the nest box (Fig 1.). In this analysis we used generalized linear models (glmer) as each vole could repeatedly visit same area around the box and nest boxes were not independent units. The count number in each area around the nest box was used as a dependent variable, interaction with infanticide and nest box manipulation as explaining fixed factors and vole id as random factor. Poisson error structure was used in this analysis. In analyzing the passivity of the voles we used Mann-Whitney U-test.

\section{Results}

Occurrence of male infanticide 
Against our prediction there was no pattern in the proportion of infanticidal males following increasing population densities over summer in the wild-caught sample of either early, mid or late summer. The trait for infanticide remained stable being $25-29 \%$ through the breeding season $\left(\chi^{2}=0.183, \mathrm{df}=2, \mathrm{p}=0.913\right.$, Table 1$)$.

\section{Nest searching behavior in males}

There was a significant interaction between infanticidal status and cue for the first choice of the nest box $\left(\chi^{2}=9.48, \mathrm{df}=3, \mathrm{p}=0.023\right)$. The first inspection of the nest boxes by infanticidal males targeted the nest with the acoustic cue of pup vocalization $\left(\chi^{2}=11.35, \mathrm{df}=\right.$ $3, \mathrm{p}=0.010)$ as the first nest inspection was more evenly distributed in non-infanticidal males $\left(\chi^{2}=3.00, \mathrm{df}=3, \mathrm{p}=0.391\right.$, Fig. 2$)$

Space use around the nest boxes during the whole 30-min observation period did not differ between infanticidal and non-infanticidal males (null model best), but infanticidal individuals were significantly more active than non-infanticidal ones measured as the proportion of moving or staying still/freeze during each minute of the observation period (Mann-Whitneyn U-test; $\mathrm{U}=344.0, \mathrm{n}_{1}=32, \mathrm{n}_{2}=32, \mathrm{p}=0.021$ ).

Four out of the total number of 64 males intruded into the nest box through the entrance tube. All of them were infanticidal.

\section{Discussion}

Successful hunting by a nest predator, or in our study the infanticidal male bank vole, is a series of behaviours from spotting a profitable resource patch (breeding territory of a female), finding the prey (the nest), conducting a successful attack (intrude the nest) and kill the pup (Caro 2005). Our study concentrated to prey searching behaviours in relation to infanticidal 
behavioural trait of male bank voles. Spotting female territories should be easy as both the female and the male have joint interest in reproduction, but opposite interests regarding the faith of current litter, assuming that the male is not the father of the litter. Here only the female has to loose. Therefore she defends her nest site fiercely against any intruding conspecific, both females and males, both infanticidal males and non-infanticidal ones (Ylönen \& Horne 2002). Any adult or sub-adult individual too close to nest forms a potential threat for the pups (Ylönen et al. 1997). The mother is able to chase away all female intruders and most males, but a proportion of large infanticidal males are able to pass the defending mother and kill the pups (Ylönen \& Horne 2002).

We focused on a situation where the nest is unprotected, placed in the cavity (nest box) with entrances and emitting indirect cues of the nest, pup vocalization, nest odour or both. Small rodents live in the world where we expected olfactory sense playing a stronger role than acoustic one. However, our results showed that infanticidal male voles targeted to nest boxes with an acoustic cue, a pup crying after its absent mother. The sound of the pup included both hearable frequencies of the vocalization but also ultra-sound, USV. We know that rodents, like the bank vole, are able to hear ultra-sound and use it in intra-specific communication, especially in communication between pups and the mother (Kober et al. 2007, Matrosova et al. 2007). However, regardless of hearable sound or ultra-sound, our results suggest that infanticidal male voles can eavesdrop communication between pups and the mother for guidance to nest, and perpetrating infanticide. That the odour cue did not attract the male to first inspection, or even hindered the inspection of the acoustic cue in the combined Odour * Sound nestbox, was unexpected. Maybe a nest approaching male regards the odour cue meaning that the mother is present in the nest, as the bedding was collected from the laboratory cage with mother and pups together living in it. Some support for this explanation 
gives the observation that control box that neither did not have female odour, was the secondly often visited, although this difference was not statistically significant. However, despite of the preference of sound cue nests also odour nests had a role for the infanticidal males. After inspections four infanticidal males intruded the nest, just like in Ylönen \& Horne's (2002) study where the mother was guarding the nest. In the present study three out of four intruding males went to odour nest and one to sound nest. This may mean, that a proportion of infanticidal males take the choice to try to intrude a nest regardless of possible aggressive nest protection by the mother.

Outside the close vicinity of the nest box there was no difference between infanticidal or noninfanticidal males in the use of the area around each box. This may be a laboratory artefact and indicate that the open arena space without other structures than the nest boxes was too simple habitat and that the cues we used only reached a short distance from the nest box. However, like shown before (Korpela et al. 2011) infanticidal males were more active in moving around and seeking the vicinity of the boxes than the non-infanticidal ones. Korpela et al. (2011) showed that the infanticidal males are more bold in personality traits than the non-infanticidal conspecifics (Korpela et al. 2010) and in field studies infanticidal males are more active and move over larger distances than non-infanticidal ones (Haapakoski et al. 2015).

Our trappings over the whole breeding season from April to August revealed the possibility to check from the captured males if the infanticidal trait varies over the breeding season. It has been suggested that infanticide could be more common, and more beneficial for the perpetrator during the high population densities (Korpela et al. 2010). This assumption follows the idea that any competition for resources, space and mates is stronger during high 
densities of competitors. However, the opposite view that infanticide following male turnover is beneficial during low densities has also gained support (Eccard \& Ylönen 2001, Andreassen \& Gundersen 2006, Opperbeck et al. 2012). This assumption rises from the benefit of a single act of infanticide to occupy proportionally more resources for own or offspring benefits as resources still are available without the intense competition of high conspecific densities. Our study is the first to monitor infanticidal behaviour along the density gradient along the whole breeding season. Our study year was a peak density year (Rikalainen 2012), when the spring densities were already high, but doubled until the late summer. Our result suggests that the proportion of male infanticide in seasonal population is very stable, around one fourth to one third of the population males being killers. Thus male infanticide forms a stable per capita threat for offspring born into the population at any time during the breeding season assuming that the proportion of the vulnerable pups also stays the same during the breeding season. Stableness of male infanticidal threat also maintains effective female counter-strategies to infanticide, like polyandry, female mating with several males, forming a potential risk for your future offspring (Klemme \& Ylönen 2010) and mother's aggressive defence of the nest towards all intruders (Ylönen \& Horne 2002).

Acknowledgements. We thank the staff of the Konnevesi Research Station for help in constructing the experimental set-up and for help in animal care. Dirk Opperbeck is acknowledged for the technical help in recording and play-back of the sound cue. This research was supported by the Academy of Finland for the Centre of Excellence in Evolutionary Ecology at the University of Jyväskylä. There is no conflict of interests between the authors.

\section{References}


Agrell, J., Wolff, J.O. \& Ylönen, H. 1998: Counter-strategies to infanticide in mammals: costs and consequences. - Oikos 83, 507-517.

Andreassen, H.P. \& Gundersen, G. 2006: Male turnover reduces population growth: an enclosure experiment on voles. - Ecology 87, 88-94.

Blumstein, D.T. 2000: The evolution of infanticide in rodents: a comparative analysis. - In: Infanticide by males and its implications (van Schaik, C.P. \& Janson, C.H., eds), Cambridge University press, Cambridge, pp 178-197.

Caro, T. 2005 : Antipredatory defences in birds and mammals. University of Chicago Press. Chicago \& London.

Cushing, B.S. 1985: Estrous mice and vulnerability to weasel predation. Ecology 66, 19761978.

Davies, N. 2015. Cuckoo - Cheating by Nature. Bloomsbury.

Eccard, J.A. \& Ylönen, H. 2001: Initiation of breeding after winter in bank voles: effects of food and population density. Can. J. Zool. 79, 1743-1753.

Haapakoski, M., Vihervaara, H., Lensu, A., Sundell, J. \& Ylönen, H. 2015: Infanticide effects on behavior of the bank vole (Myodes glareolus) in the fragmented breeding habitat. - Behav. Ecol. Sociobiol. 69, 49-59.

Hausfater, G. \& Hrdy, S. B. (eds) 1984: Infanticide: comparative and evolutionary perspectives. Aldine Press, New York.

Hausfater, G. \& Hrdy, S.B. 2008: Infanticide: Comparative and evolutionary perspectives. Transaction Publisher. 637p. ISBN: 978-0-202-36221-2

Horne, T. \& Ylönen, H.1996: Mating behaviour and female choice in relation to male social status in the bank vole (Clethrionomys glareolus) Behav. Ecol. Soc. 38, 401-405.

Horne, T.J. \& Ylönen, H. 1998: Heritabilities of dominance related traits in the male bank vole (Clethrionomys glareolus) Evolution 52, 894-899.

Järvinen, A. 1985. Predation causing extended low densities in microtine cycles: implications from predation on hole-nesting passerines. Oikos 45, 157-158.

Ichikawa, N. 1994: Male counterstrategy against infanticide of the female giant water bug Lethocerus deyrollei (Hemiptera: Belostomatidae). J. Insect Behav.8,181-188.

Klemme, I. \& Ylönen, H. 2010: Polyandry enhances offspring survival in an infanticidal species. Biol. Lett. 6, 24-26.

Klemme, I., Kataja-aho, S., Eccard, J.A. \& Ylönen, H. 2012: Variable mode of estrus affects female decision for multiple mating. Behav. Ecol. 23, 361-367. 
Kober, M., Trillmich, F. \& Naguib, M. 2007: Vocal mother-pup communication in guinea pigs: effects of call familiarity and female reproductive state. Anim. Behav. 73, 917-925.

Korpela, K., Sundell, J. \& Ylönen, H. 2010: Density dependence of infanticide and recognition of pup sex in male bank voles. Behaviour 147, 871-881.

Korpela, K., Sundell, J. \& Ylönen, H. 2011: Does personality in small rodents vary depending on population density? Oecologia 165, 67-77.

Krebs, C.J. 2003. Beyond population regulation and limitation. Wildl. Res. 29, 1-10

Liesenjohann, M., Liesenjohann, T., Trebaticka, L., Haapakoski, M., Sundell, J., Ylönen, H., \& Eccard, J. A. 2011 : From interference to predation: type and effects of direct interspecific interactions of small mammals. Behav. Ecol. Sociobiol.65, 2079-2089.

Lukas, D. \& E. Huchard. 2014. The evolution of infanticide by males in mammalian societies. Science 346, 841-844.

Matrosova, V.A., Volodin, I.A., Volodina, E.V. \& Babitsky, A.F. 2007: Pups crying bass: vocal adaptation for avoidance of age-dependent predation risk in ground squirrels? Behav. Ecol. Sociobiol. 62:181-191.

McCarthy, M. M. \& F. S. Vom Saal. 1986a. Inhibition of infanticide after mating by wild male house mice. Physiology and Behavior 36, 203-209.

Møller, A.P. 1988: Infanticidal and anti-infanticidal strategies in the swallow Hirundo rustica. Behav. Ecol. Sociobiol. 22, 365-371.

Opperbeck, A., Klemme, I. \& Ylönen, H. 2012: Infanticide and population growth in the bank vole (Myodes glareolus): the effect of male turnover and density. Ethology 118, 178186.

Perrigo, G., Belvin, L., Quindry, P., Kadir, T., Becker, J., van Look, C., Niewoehner, J. \& vom Saal, F.S. 1993: Genetic mediation of infanticide and parental behavior in male and female domestic and wild stock house mice. Behav. Genet. 23, 525-531.

R Core Team 2015: R: A language and environment for statistical computing. R Foundation for Statistical Computing, Vienna, Austria. URL https://www.R-project.org/.

Rikalainen, K. 2013: Genetic diversity in the wild. Cyclic population dynamics and population isolation. - Jyväskylä Studies in Biological and Environmnetal Science 258. 50 p.

Robertson, R.J. \& Stutchbury, B.J. 1988: Experimental evidence for sexually selected infanticide in tree swallows. Anim. Behav. 36, 749-753.

Schneider, J.M. \& Lubin, Y. 1996: Infanticidal male eresid spiders. Nature 381:655-656

Schneider, J. M. \& Lubin, Y. 1997. Infanticide by males in a spider with suicidal maternal care, Stegodyphus lineatus (Eresidae). Anim. Behav. 54, 305-312. 
Smith, J.C. 1972: Sound production by infant Peromyscus maniculatus (Rodentia: Myomorpha). J. Zool. 168, 369-379.

Spottiswoode, C.N. \& Koorevaar, J. 2011: A stab in the dark: chick killing by brood parasitic honeyguides. Biol. Lett. 8, 241-244.

van Schaik C.P. \& Janson, C.H. 2000: Infanticide by males. Cambridge Univ. Press., Cambridge, 569p.

Vihervaara, H., Sundell, J. \& Ylönen, H. 2010: Is mating alone enough to inhibit infanticide in male bank voles? Ethology 116, 888-894.

Weatherhead, P. J., \& Blouin-Demers, G. 2004: Understanding avian nest predation: why ornithologists should study snakes. Journal of Avian Biology 35, 185-190.

Wolff, J.O. 1993: Why are female small mammals territorial. Oikos 68, 364-370.

Wöhr, M., Dahlhoff, M., Wolf, E., Holsboer, F., Schwarting, R.K.W. \& Wotjak, C.T. 2008: Effects of genetic background, gender, and early environmental factors on isolation-induced ultrasonic calling in mouse pups: an embryo-transfer study. Behav. Genet. 38, 579-595.

Ylönen, H., \& Ronkainen, H. 1994: Breeding suppression in the bank vole as antipredatory adaptation in a predictable environment. Evol. Ecol. 8, 658-666.

Ylönen, H., Koskela, E. \& Mappes, T. 1997: Infanticide in the bank vole (Clethrionomys glareolus): occurrence and the effect of familiarity on female infanticide. Ann. Zool. Fennici 34:259-266.

Ylönen, H. \& Horne, T.J. 2002: Infanticide and effectiveness of pup protection in bank voles: does the mother recognize a killer? Acta Ethol. 4, 97-101.

Ylönen, H. \& Brown, J.S. 2007. Fear and the Foraging, Breeding and Sociality in Rodents. In: Rodent Societies (Wolff, J.O. \& Sherman, P.W., eds) University of Chicago Press, Chicago, pp. 328-341. 
Table 1. Proportion of infanticidal (Infa+) and non-infanticidal (Infa-) males in wild-caught bank voles in Spring (April-May captures), Early summer (June captures) and Late summer (July - August captures) 2011. The year resembled a peak population density of cyclic bank vole populations in Central Finland, but during our study period the population had a typical annual increase and doubled from May until August (Rikalainen 2013). In total 118 males were tested for their infanticidal trait.

Spring N, \% Early summer N, \% Late summer N, \%

\begin{tabular}{lllllll} 
Infa + & 20 & 29.4 & 5 & 25.0 & 8 & 26.6 \\
Infa - & 48 & 70.6 & 15 & 75.0 & 22 & 73.4 \\
\hline Tot. & 68 & 100.0 & 20 & 100.0 & 30 & 100.0
\end{tabular}




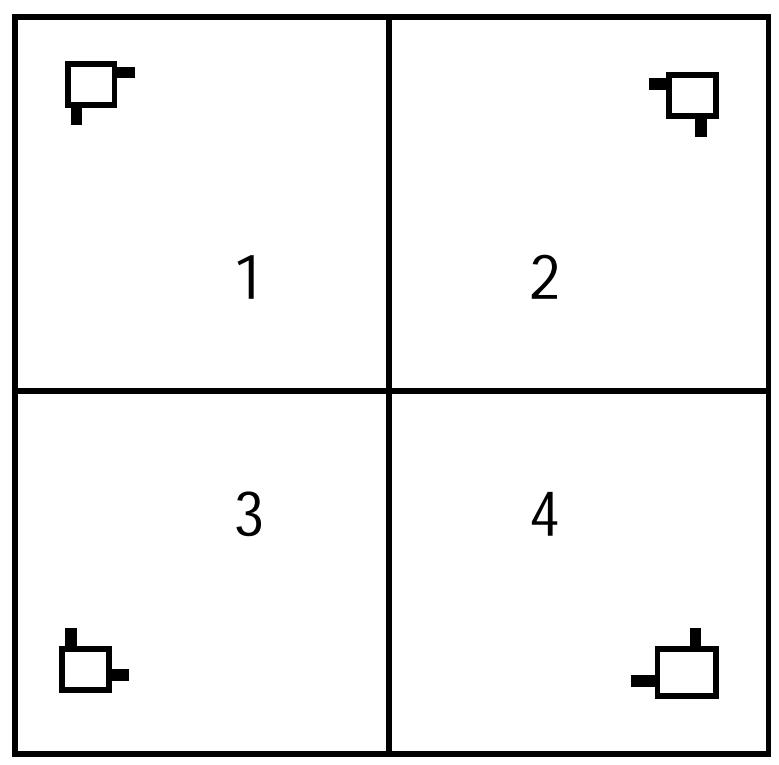

Fig. 1. Test arena of $7 \times 7$ meters with the nest boxes providing each a different nesting cue 1 $=$ Sound (play-back of pup vocalization including range hearable for humans but also ultrasounds, USV), 2 = Odour (fresh bedding from next box with mother and pups), 3 = Both sound and odour combined. $4=$ Control (artificial sound of same intensity like pup vocalization and no odor cue). The space is divided into squares around the nest boxes to measure movement activity of the males. 


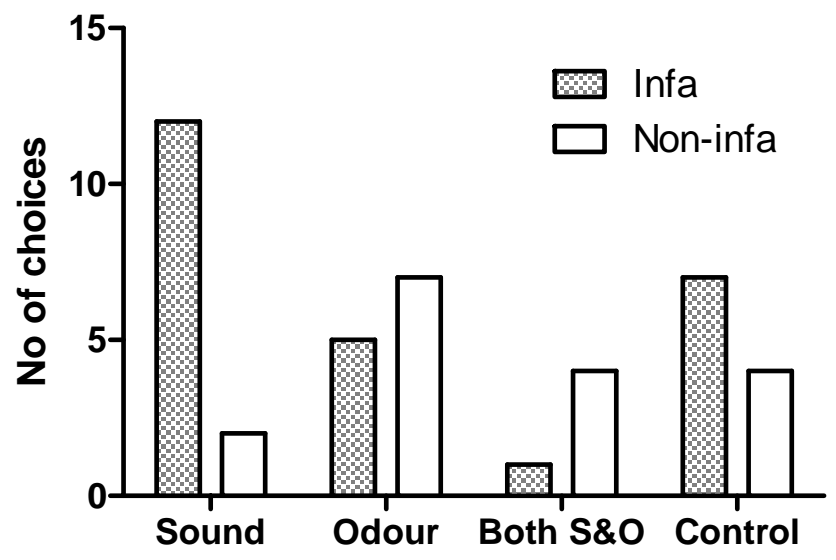

Fig. 2. Infanticidal and non-infanticidal males' first choices for the nest boxes with different nest cues 